\title{
SURFACE MODIFICATION OF SELF-CONSOLIDATED MICROPOROUS Ti IMPLANT COMPACTS FABRICATED BY ELECTRO-DISCHARGE-SINTERING IN AIR
}

\begin{abstract}
A single pulse of $0.75-2.0 \mathrm{~kJ} / 0.7 \mathrm{~g}$ of atomized spherical Ti powders from $300 \mathrm{mF}$ capacitor was applied to produce a microporous Ti implant compact by electro-discharge-sintering (EDS). A solid core in the middle of the compact surrounded by a microporous layer was found. X-ray photoelectron spectroscopy was employed to study the surface characteristics of the EDS Ti compact and it revealed that $\mathrm{Ti}, \mathrm{C}$ and $\mathrm{O}$ were the main constituents on the surface with a smaller amount of $\mathrm{N}$. The surface was lightly oxidized and was primarily in the form of $\mathrm{TiO}_{2}$ resulting from the air oxidation during EDS processing. The lightly oxidized surface of the EDS compact also exhibited Ti nitrides such as TiN and TiON, which revealed that the reaction between air constituents and the Ti powders even in times as short as $128 \mathrm{msec}$.
\end{abstract}

Keywords: Titanium, Implant, Porous, Sintering, X-ray photoelectron spectroscopy (XPS)

\section{Introduction}

Porous-surfaced Ti implants have been developed to provide high surface area for the promotion of immobilization of the implant in bone by enabling mechanical interlocking between the implant and tissue, leading to faster osseointegration. For fabrication of porous-surfaced Ti implants, the usual sequence in powder metallurgy operations is to compact a metal powder in a die at room temperature and subsequently sinter it at elevated temperatures. Not only are high pressures, high temperatures, and long times required, but in the case of reactive materials, such as Ti and Ti-6Al-4V, an inert atmosphere is also inevitably required $[1,2]$. The high temperatures involved in these processes may result in detrimental changes in the microstructure and mechanical properties [1].

In addition to pore size and motion at the tissue-implant interface, the surface properties of the implant will affect tissue integration $[3,4]$. Therefore, surface treatments of Ti and Tibased alloys have been intensively studied and widely reported in order to improve their surface characteristics. These cover a wide range of techniques, such as spraying, plating, chemical conversion coating, physical vapor deposition, laser surface modification, etc. [5-7], each with its own merits and limitations. Among them, nitriding processes based on the thermo-diffusion mechanism have been used to improve the corrosion and wear resistance properties as well as bioactivity of $\mathrm{Ti}$ and Ti-based alloys, resulting from the formation of Ti nitrides. Conventional nitriding processes have several disadvantages, however, such as long processing times, poor surface finish, poor control of the nitride layer formation etc $[8,9]$.

To overcome these problems, therefore, we have first introduced the electro-discharge-sintering (EDS) which combines simultaneous compaction and sintering of Ti powders by applying a high voltage and high density current without external pressure.

Since important surface characteristics of metallic biomaterials include composition and structure of the surface oxide and contamination of the surface $[10,11]$, in this study, we investigated the surface characteristics of Ti compacts prepared by the EDS method and compared to those of a conventional Ti sintering system.

\section{Experimental}

Atomized Ti spherical powders (Grade II), produced by the rotating electrode process (TLS Technik, Germany), were sieved to yield one particle size class of 150-200 $\mu \mathrm{m}$. 0.7 gram of powder was vibrated into a quartz tube with an inner diameter of $4.0 \mathrm{~mm}$ that had a tungsten electrode at the bottom. $\mathrm{A} \mathrm{Cu}$ heat sink tube was placed into the quartz mold. An upper electrode was automatically machined-driven on the top of the powder column followed by applying a load of $10 \mathrm{~kg}$. One

\footnotetext{
SEJONG UNIVERSITY, FACULTY OF NANOTECHNOLOGY AND ADVANCED MATERIALS ENGINEERING, SEOUL 05000, KOREA

** WONKWANG HEALTH SCIENCE UNIVERSITY, DEPARTMENT OF DENTAL LABORATORY, IKSAN 54538, KOREA

*** KOREA AEROSPACE UNIVERSITY, DEPARTMENT OF MATERIALS ENGINEERING, GOYANG-SI 10510, KOREA

**** UIDUK UNIVERSITY, DIVISION OF GREEN ENERGY ENGINEERING, KYEONGJU 38004, KOREA

***** COLORADO SCHOOL OF MINES, DEPARTMENT OF METALLURGICAL AND MATERIALS ENGINEERING, GOLDEN 80401, USA 
capacitor bank of $300 \mu \mathrm{F}$ was charged with $0.75-2.0 \mathrm{~kJ}$ in input energy. The charged capacitor bank instantaneously discharged through the powder column by an on/off high vacuum switch which closes the discharge circuit. The voltage and current that the powder column experiences, when the circuit is closed, are simultaneously picked up by a high voltage probe and a high current probe, respectively.

EDS compacts obtained from current experimental condition were sliced every two millimeters and their cross-sections were examined with a scanning electron microscope (SEM). $\mathrm{X}$-ray photoelectron spectroscopy (XPS) has been employed to examine the surface chemical composition of the microporous Ti implant compact. The XPS spectra were taken in the porous layer consisted of powder particles that were connected by necks.

\section{Results and Discussion}

Fig. 1 shows both the dependence of the surface morphology $(\mathrm{a}, \mathrm{b})$ and the cross section views $(\mathrm{c}, \mathrm{d})$ of an EDS Ti compact as a function of input energy. Both revealed typical microporous features. Fig. 1c shows that a fully microporous compact can be obtained without forming a solid core by the discharge with an input energy of $0.75 \mathrm{~kJ}$. However, when an input energy of $1.5 \mathrm{~kJ}$

(a)

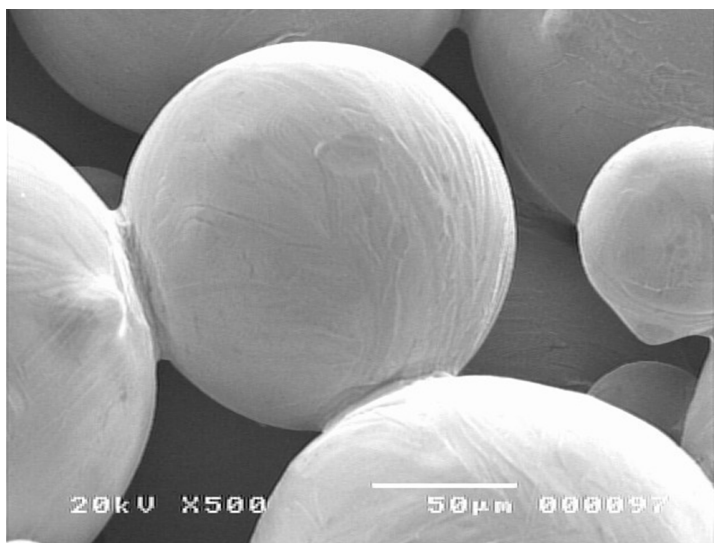

(c)

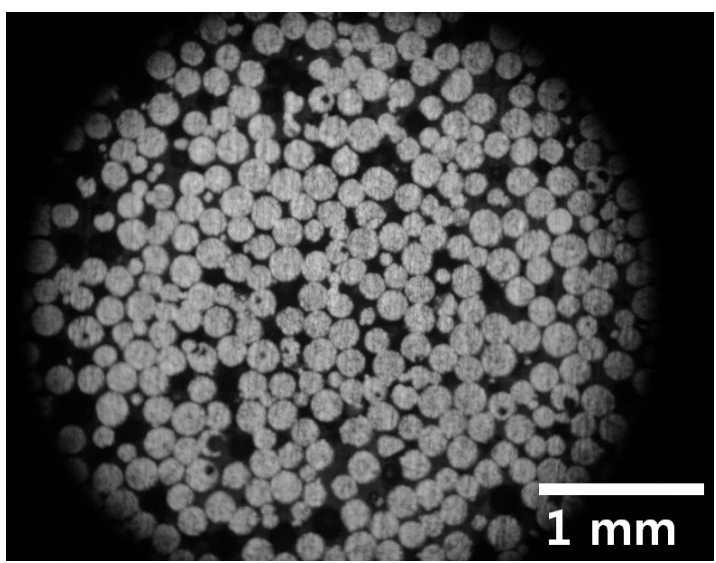

revealed that the formation of a solid core was observed in the center of the compact which was surrounded by a microporous layer (Fig. 1d). The solid core was composed of powder particles which were deformed and welded together. The porous layer consisted of powder particles that were connected only by necks in three dimensions as shown in (Fig. 1a,b).

The dependence of average pore sizes as a function of input energy varied from 122.3 to $98.5 \mu \mathrm{m}$ with the input energy of $0.75 \mathrm{~kJ}$ and $1.5 \mathrm{~kJ}$, respectively. The porosities of the compacts were also estimated to be about 20.1-37.3\%. Both pore size and porosity were decreased with an increase in input energy. The thickness of the porous layer can be controlled by the input energy. With decreasing the input energy, the thickness of porous layer increases. The increased porous layer can provide more contact area with bone, resulting in fast and strong osseointegration [3].

Fig. 2 shows typical optical micrographs of the solid core and powders in the porous layer of the EDS microporous-surfaced Ti compact discharged with input energy of $1.5 \mathrm{~kJ}$. Both solid core and powders in the porous layer exhibited similar microstructure of $\mathrm{cp} \mathrm{Ti}$, which was annealed in the beta region and quenched in the water [12]. It can thus be expected that EDS does not change the unique microstructure of as-received Ti powder.

(b)

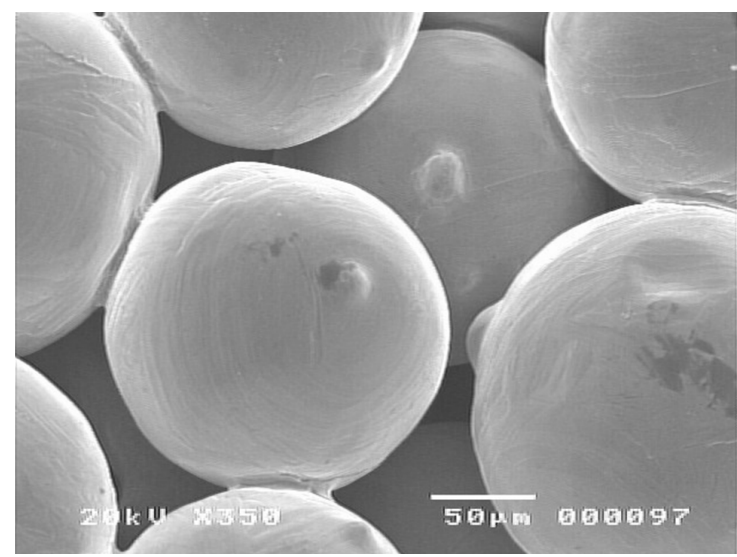

(d)

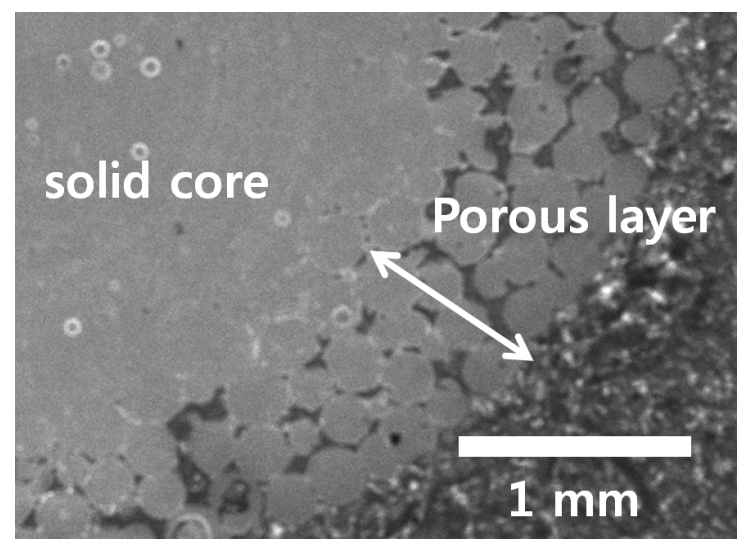

Fig. 1. Surface (a) and (b) and cross-section (c) and (d) micrographs of EDS compact discharged at $0.75 \mathrm{~kJ}$ (a) and (c) and $1.5 \mathrm{~kJ}$ (b) and (d) of input energy, respectively 
(a)

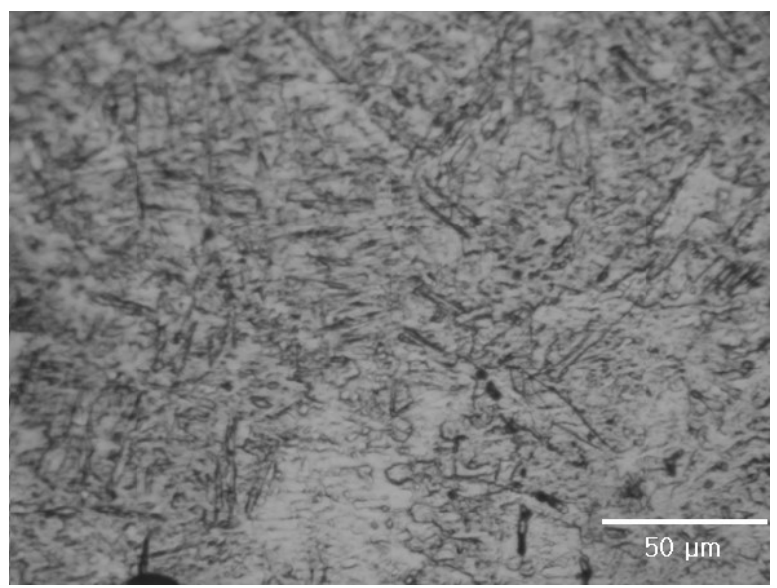

(b)

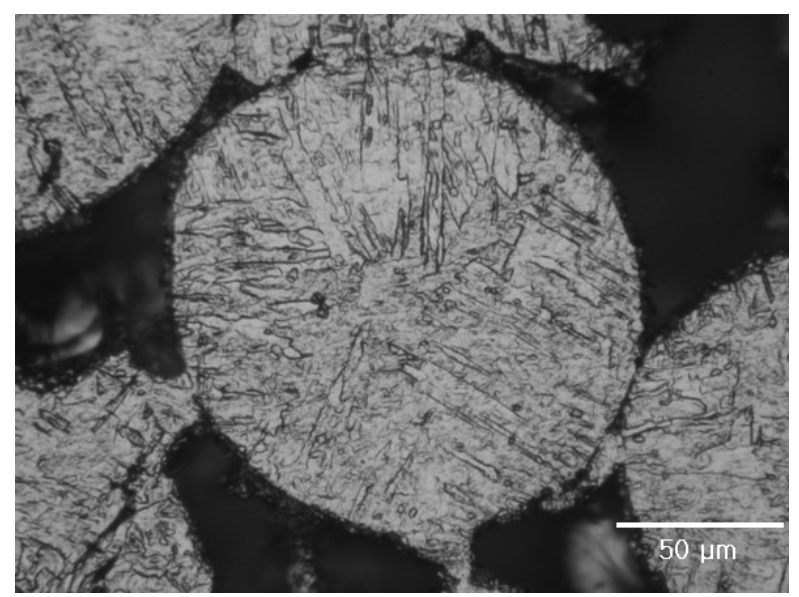

Fig. 2. Optical micrographs of (a) the solid core and (b) powders in the porous layer of EDS compact discharged at $1.5 \mathrm{~kJ}$ in input energy

Fig. 3 shows two wide scan XPS spectra of the EDS compact and the as-received Ti powder before discharge. The main constituents of $\mathrm{Ti}, \mathrm{O}$ and $\mathrm{C}$ were observed in the case of as-received Ti powder. However, the EDS compact showed a distinct $\mathrm{N} 1 \mathrm{~s}$ peak at about $400 \mathrm{eV}$. Both the as-received Ti powder and the EDS compact were further analyzed by combining $\mathrm{Ar}^{+}$ sputtering with XPS measurements. Although different features such as preferential sputtering, atomic mixing, particle size effects, etc., can affect the etching profiles, similar etching rates of the Ti were observed in other studies [13,14]. High resolution scans were then used to obtain information regarding the surface chemical state of the materials.

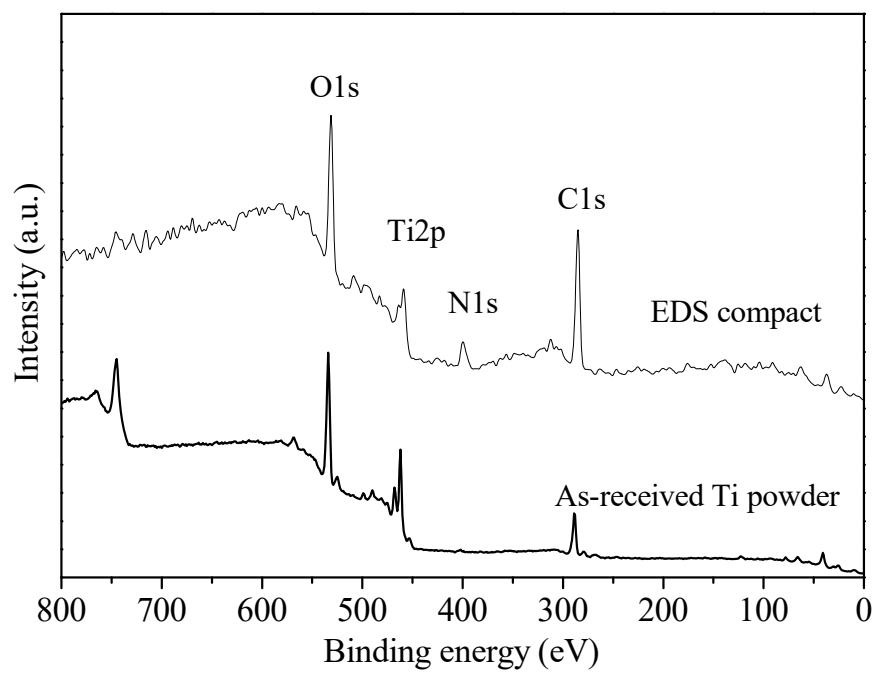

Fig. 3. XPS survey spectra of as-received Ti powder and EDS compact.

Fig. 4 shows narrow scan spectra of the Ti $2 p$ region before and after etching of the as-received Ti powder and EDS compact discharged with input energy of $1.5 \mathrm{~kJ}$. Before etching, a Ti $2 \mathrm{p}_{3 / 2}$ peak at $458.4 \mathrm{eV}$ is shown in the as-received Ti powder, with $5.8 \mathrm{eV}$ splitting between the Ti $2 \mathrm{p}_{1 / 2}$ and Ti $2 \mathrm{p}_{3 / 2}$ peaks. Previous results on Ti narrow scan spectra of wrought Ti and Ti alloy showed a Ti $2 \mathrm{p}_{3 / 2}$ peak at about $459.2 \mathrm{eV}$ with $5.8 \mathrm{eV}$ splitting between the Ti $2 \mathrm{p}_{1 / 2}$ and $\mathrm{Ti} 2 \mathrm{p}_{3 / 2}[15,16]$. For $\mathrm{Ti}^{4+}$ in $\mathrm{TiO}_{2}$, the Ti $2 \mathrm{p}_{3 / 2}$ peak is at about $459.1 \mathrm{eV}$. Peak shifts for $\mathrm{Ti}^{3+}\left(\mathrm{Ti}_{2} \mathrm{O}_{3}\right)$, $\mathrm{Ti}^{2+}(\mathrm{TiO})$, and $\mathrm{Ti}$ (metal) are approximately $-1.7,-3.5$, and $-5.2 \mathrm{eV}$, respectively $[17,18]$. In the EDS compact, the Ti $2 \mathrm{p}_{3 / 2}$ peak is also observed at about $458.4 \mathrm{eV}$. Thus, the surfaces of the as-received Ti powder and EDS compact are primarily in the form of $\mathrm{TiO}_{2}$. On the other hand, the surface spectrum of the as-received Ti powder after etching revealed the broad shoulder region at about 453.5 and $454.8 \mathrm{eV}$ that indicates the presence of metallic Ti and Ti nitride, respectively. However, a lightly etched EDS compact showed a Ti $2 \mathrm{p}_{3 / 2}$ peak at $454.2 \mathrm{eV}$, with $6.0 \mathrm{eV}$ splitting between the Ti $2 p_{1 / 2}$ and Ti $2 p_{3 / 2}$ peaks. This indicates that the surface is primarily in the form of Ti nitrides, such as TiN and TiON. It was reported that plasma enhanced chemical vapor deposition (PECVD) can produce the TiN as well as the $\mathrm{TiN}_{\mathrm{x}} \mathrm{O}_{\mathrm{y}}$ phase in nitride layer [19]. The formation of oxynitride layers on Ti with gas diffusion treatment has been also reported [20]. On the other hand, the EDS process can modify the original surface of as-received powder from $\mathrm{TiO}_{2}$ to Ti nitrides in $128 \mu \mathrm{sec}$. This result can be attributed to the fact that the high input energy of EDS can break down the surface oxide film of the as-received Ti powder and the fresh metallic surface of the compact subsequently react with residual oxygen and nitrogen, forming Ti nitrides during the discharge process [21].

High resolution spectra of the $\mathrm{O} 1 \mathrm{~s}$ region for the as-received Ti powder and ESD compact before and after an etching are shown in Fig. 5. In the case of as-received Ti powder, the main component at about $530.1 \mathrm{eV}$ can be assigned to oxygen from the $\mathrm{TiO}_{2}$. The broad shoulder extending from 531 to $534 \mathrm{eV}$ consists of two possible types of oxygen sites such as C-O-C and $>\mathrm{C}=\mathrm{O}$ groups [22]. There were no significant differences in the peak intensity of $\mathrm{O} 1 \mathrm{~s}$ before and after etching of as-received Ti powder, indicating an existence of thick Ti oxide in nature. A peak shift of the $\mathrm{O} 1 \mathrm{~s}$ from 530.1 to $530.5 \mathrm{eV}$ after an etching is considered to be due to an existence of Ti oxynitride. In the case of EDS compact, the main component at about $530.1 \mathrm{eV}$ 
(a)

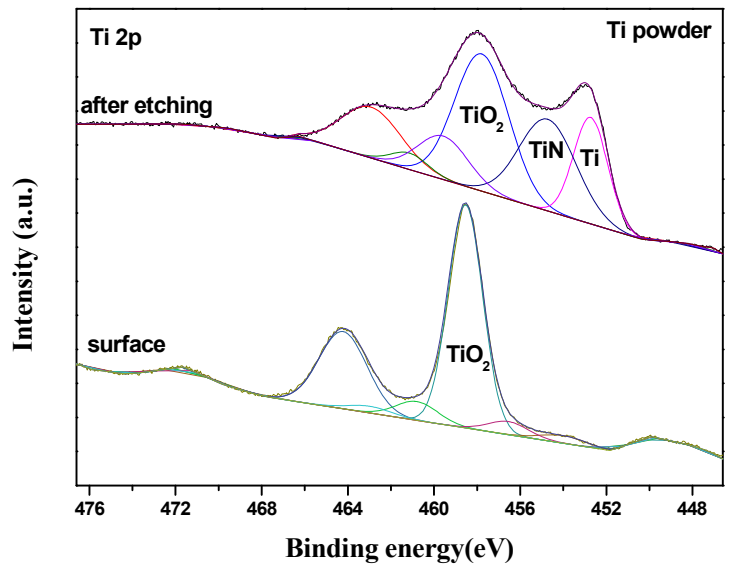

(b)

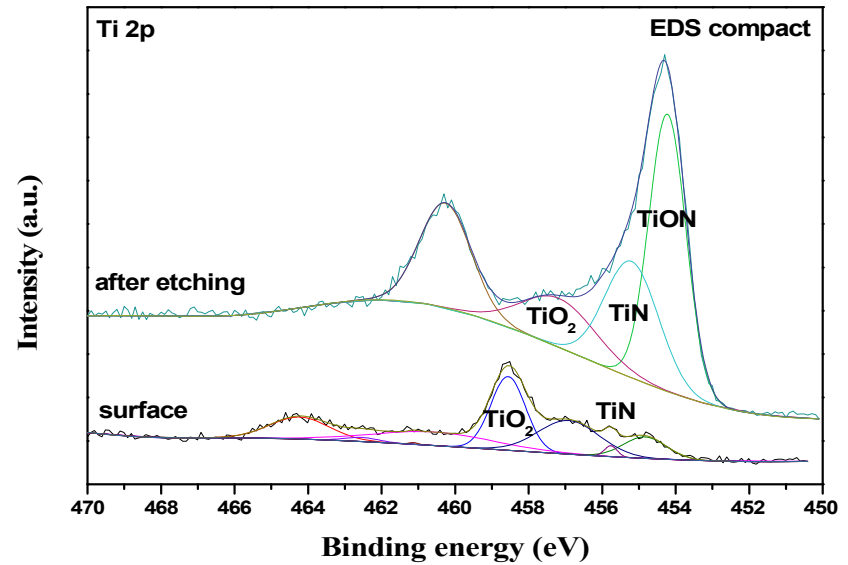

Fig. 4. XPS high resolution spectra of the Ti $2 p$ region before and after $\mathrm{Ar}^{+}$etching of (a) as-received Ti powder and (b) compact discharged at $1.5 \mathrm{~kJ}$ of input energy

is also assigned to oxygen from the $\mathrm{TiO}_{2}$. Oxygen and moisture from the laboratory environment is expected to contribute the region 531-534 eV. Etching the EDS compact significantly decreased the peak intensity, which result is consistent with the Ti $2 p$ spectra as shown in Fig. 4. This also supports that the EDS compact is slightly oxidized.

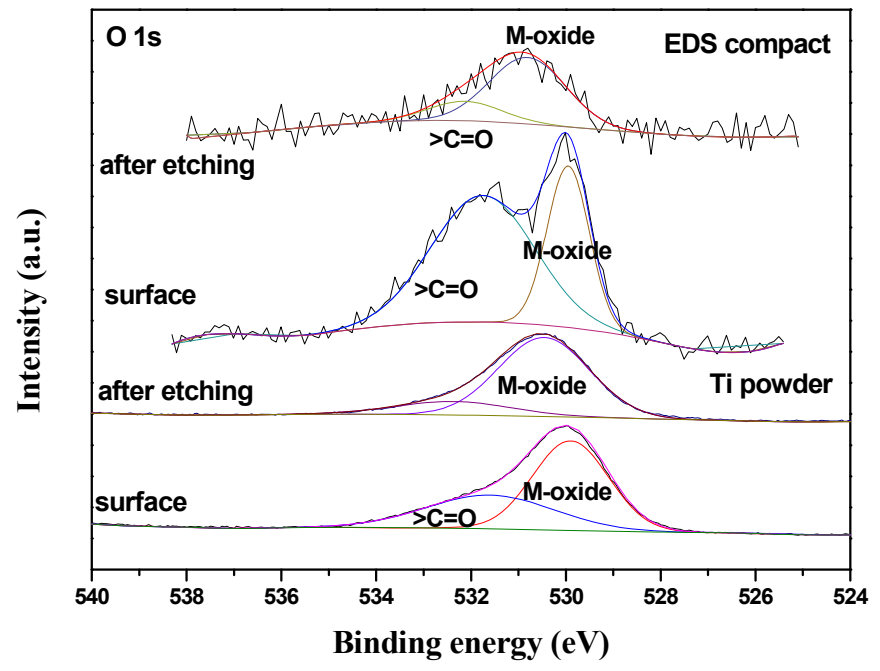

Fig. 5. XPS high resolution spectra of the $\mathrm{O} 1 \mathrm{~s}$ region before and after $\mathrm{Ar}^{+}$etching of as-received Ti powder and EDS compact discharged at $1.5 \mathrm{~kJ}$ of input energy

Fig. 6 shows representative high resolution spectra of the $\mathrm{N} 1$ s region for the as-received powder and EDS compact before and after etching. The peak positions at 399.9 and $396.8 \mathrm{eV}$ are identical to the $\mathrm{N}$ 1s peaks of adsorbed organic nitrogen and nitride, respectively. This result indicates the presence of significant amount of nitride in the case of the EDS compact after etching, and supports assignment of Ti nitride peaks to the Ti $2 p$ spectrum. In the EDS process, as soon as heat is generated and is accumulated through the Ti powder column by the discharge, the heat dissipates fast throughout the $\mathrm{Cu}$ heat sink.
The temperature of the compact taken out of the chamber just after a discharge was measured to be about $90^{\circ} \mathrm{C}$, which is not high enough to react with nitrogen in air for the formation of nitrides. The formation of Ti nitrides can thus be explained by the electrical discharge in air, resulted from the reaction between nitrogen and the Ti surface during the discharge.

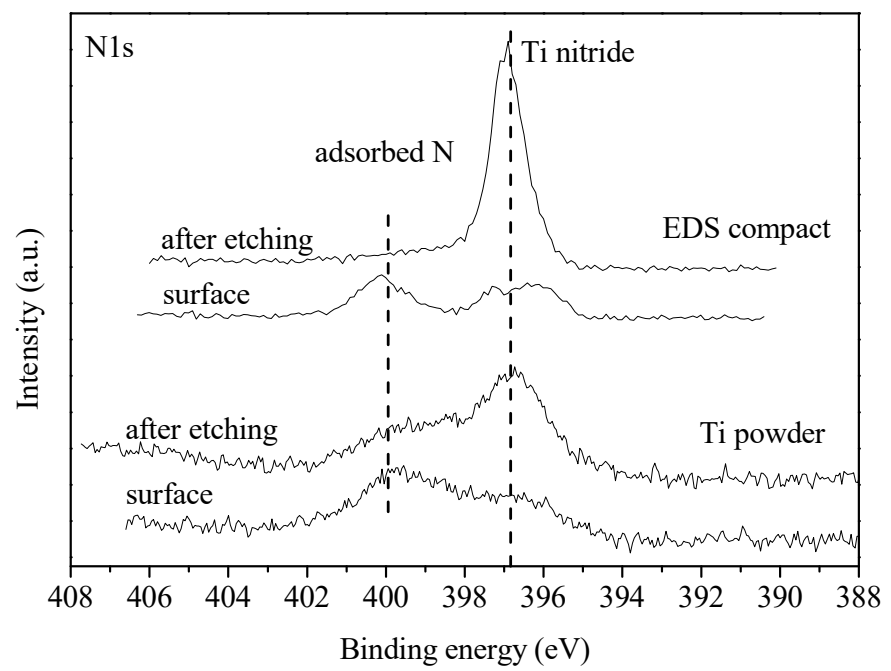

Fig. 6. XPS high resolution spectra of the $\mathrm{N} 1 \mathrm{~s}$ region before and after $\mathrm{Ar}^{+}$etching of as-received Ti powder and EDS compact discharged at $1.5 \mathrm{~kJ}$ of input energy

It is summarized that the surface of EDS Ti compact was lightly oxidized and was primarily in the form of $\mathrm{TiO}_{2}$ (B.E.: $458.4 \mathrm{eV}$ ) resulting from the air oxidation during an EDS process. The lightly oxidized surface of the EDS compact also exhibited Ti nitrides such as TiN (B.E.: $454.8 \mathrm{eV}$ ) and TiON (B.E.: $454.3 \mathrm{eV}$ ), which revealed that the reaction between air constituents and the Ti powders even in times as short as $128 \mu \mathrm{sec}$. 


\section{Conclusions}

Electro-discharge-sintering (EDS) in air was employed to fabricate the microporous Ti implant compacts from atomized Ti powders, which were subjected a discharge of 0.75-2.0 kJ/0.7 g-powder from $300 \mu \mathrm{F}$ capacitor bank. The solid core was automatically formed in the center of the compact and microporous layer consisted of particles connected in three dimensions by necks. The surface of EDS compact was lightly oxidized and was primarily in the form of $\mathrm{TiO}_{2}$. Ti nitride surface was obtained through a light etching process, indicating that the EDS broke down the original oxide film of the as-received Ti powder during the discharge process. The lightly oxidized surface of the compact could be the result of the reaction with oxygen during instant heat generation by the EDS process. The presence of $\mathrm{Ti}$ nitrides also results from the reaction between nitrogen in air and the Ti substrate.

\section{REFERENCES}

[1] M.M. Dewidar, J.K. Lim, J. Alloys Comp. 454, 442 (2008).

[2] H.R. Choi, J.M. Byun, M.J. Suk, S.T. Oh, Y.D. Kim, J. Korea Powder Metall. Inst. 23, 235, (2016).

[3] B. Otsuki, M. Takemoto, S. Fujibayashi, M. Neo, T. Kokubo, T. Nakamura, Biomater. 27, 5892 (2006).

[4] K. Gomi, J.E. Davies, J. Biomed. Mater. Res. A 27, 429 (1993).

[5] F.J.C. Braga, R.F.C. Marques, E. de A. Filho, A.C. Guastaldi, Appl. Surf. Sci. 253, 9203, (2007).

[6] H.C. Man, M. Bai, F.T. Cheng, Appl. Surf. Sci. 258, 436 (2011).
[7] S.Y. Kwak, H.G. Kim, J.M. Byun, J.H. Park, M.J. Suk, S.T. Oh, Y.D. Kim, J. Korea Powder Metall. Inst. 21, 28 (2014).

[8] S. Gokul Lakshami, D. Arivuoli, B. Ganguli, Mater. Chem. Phys. 76, 187 (2002).

[9] M. Rahman, I. Reid, P. Duggan, D.P. Dowling, G. Hughes, M.S.J. Hashmi, Surf. Coat. Technol. 210, 4865 (2007).

[10] W.H. Lee, Y.J. Jo, Y.H. Kim, Y.H. Jo, J.G. Seong, C.J. Van Tyne, S.Y. Chang, Arch. Metall. Mater. 60, 1185 (2015).

[11] Y.J. Jo, Y.H. Kim, Y.H. Jo, J.G. Seong, S.Y. Chang, P.J. Reucroft, S.B. Kim, W.H. Lee, Metals Mater. Int., 21, 337 (2015).

[12] M. Donachie, Titanium, A technical guide, Ohio ASM International; 2000 p. 14.

[13] G. Soto, Appl. Surf. Sci. 233, 115 (2004).

[14] J.Y. Kim, P.J. Reucroft, M. Taghiei, V.R. Pradhan, I. Wender, Energy and Fuels 8, 886 (1994).

[15] Y.J. Jo, Y.H. Kim, Y.H. Jo, J.G. Seong, Y.K. Ko, S.B. Kim, S.Y. Chang, W.H. Lee, Metals Mater. Int. 21, 159 (2015).

[16] Y.J. Jo, Y.H. Jo, J.G. Seong, Y.H. Kim, S.Y. Chang, M.S. Noh, H.G. Jeong, W.H. Lee, Surf. Eng. 31, 885 (2015).

[17] L. Liuhe, X. Lifang, M. Xinxin, Surf. Coat. Technol. 120, 618 (1999).

[18] Y.J. Jo, Y.H. Kim, Y.H. Jo, J.G. Seong, S.Y. Chang, C.J. Van Tyne, W.H. Lee, J. Nanosci. Nanotechnol. 14, 8429 (2014).

[19] M. Rahman, I. Reid, P. Duggan, D.P. Dowling, G. Hughes, M.S.J. Hashimi, Surf. Coat. Technol. 210, 4865 (2007).

[20] O.I. Yaskiv, I.M. Pohrelyuk, V.M. Fedirko, D.B. Lee, O.V. Tkachuk, Thin Solid Films 519, 6508 (2011).

[21] Y.J. Jo, Y.H. Jo, J.G. Seong, Y.H. Kim, S.Y. Chang, W.H. Lee, Mater. Sci. Technol. 31, 989 (2015).

[22] D. Georgiev, R.J. Baird, G. Newaz, G. Auner, R. Witte, H. Herfurth, Appl. Surf. Sci. 236, 71 (2004). 